Volume 8

Issue 4 - Cancer Screening

Article 3

10-18-2021

\title{
Communication Skills Training: A Means to Promote Time- Efficient Patient-Centered Communication in Clinical Practice
}

Else Dalsgaard Iversen

Maiken Wolderslund

Poul-Erik Kofoed

Pål Gulbrandsen

Helle Poulsen

Søren Cold

Jette Ammentorp

Follow this and additional works at: https://aah.org/jpcrr

Part of the Health Communication Commons, Health Services Administration Commons, Health

Services Research Commons, Interprofessional Education Commons, and the Primary Care Commons

\section{Recommended Citation}

Iversen ED, Wolderslund M, Kofoed PE, Gulbrandsen P, Poulsen H, Cold S, Ammentorp J. Communication skills training: a means to promote time-efficient patient-centered communication in clinical practice. $J$ Patient Cent Res Rev. 2021;8:307-14. doi: 10.17294/2330-0698.1782

Published quarterly by Midwest-based health system Advocate Aurora Health and indexed in PubMed Central, the Journal of Patient-Centered Research and Reviews (JPCRR) is an open access, peer-reviewed medical journal focused on disseminating scholarly works devoted to improving patient-centered care practices, health outcomes, and the patient experience. 


\title{
Communication Skills Training: A Means to Promote Time-Efficient Patient-Centered Communication in Clinical Practice
}

\author{
Else Dalsgaard Iversen, MD, PhD, , 1,2,3 Maiken Wolderslund, PhD, MHSc, ${ }^{1,2}$ Poul-Erik Kofoed, \\ MD, PhD, ${ }^{4}$ Pål Gulbrandsen, MD, PhD, ${ }^{5,6}$ Helle Poulsen, MHSc, ${ }^{7}$ Søren Cold, MD, PhD, ${ }^{8}$ \\ Jette Ammentorp, PhD, MHSc ${ }^{1,2}$ \\ ${ }^{1}$ Health Services Research Unit, Lillebaelt Hospital, University Hospital of Southern Denmark, Vejle, Denmark; ${ }^{2}$ Institute \\ for Regional Health Research, University of Southern Denmark, Odense, Denmark'; ${ }^{3}$ Odense Patient data Explorative \\ Network (OPEN), Odense University Hospital, Odense, Denmark; ${ }^{4}$ Department of Paediatrics and Adolescent \\ Medicine, Lillebaelt Hospital, University Hospital of Southern Denmark, Vejle, Denmark; ${ }^{5}$ Institute of Clinical Medicine,

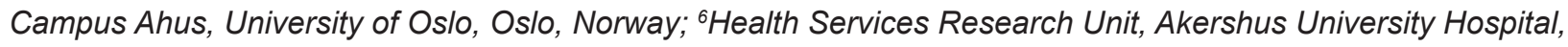 \\ Lørenskog, Norway; 'Department of Gastrointestinal Surgery, Lillebaelt Hospital, University Hospital of Southern \\ Denmark, Vejle, Denmark; ${ }^{8}$ Department of Oncology, Odense University Hospital, Odense, Denmark
}

\begin{abstract}
Purpose
We hypothesized that health care providers would behave in a more patient-centered manner after the implementation of communication skills training, without causing the consultation to last longer.

Methods

This study was part of the large-scale implementation of a communication skills training program called "Clear-Cut Communication With Patients" at Lillebaelt Hospital in Denmark. Audio recordings from real-life consultations were collected in a pre-post design, with health care providers' participation in communication skills training as the intervention. The training was based on the Calgary-Cambridge Guide, and audio recordings were rated using the Observation Scheme- 12.
\end{abstract}

Results Health care providers improved their communication behavior in favor of being more patient-centered. Results were tested using a mixed-effect model and showed significant differences between pre- and postintervention assessments, with a coefficient of $1.3(95 \% \mathrm{Cl}$ : $0.35-2.3 ; \mathrm{P}=0.01)$ for the overall score. The consultations did not last longer after the training.

Conclusions Health care providers improved their communication in patient consultations after the implementation of a large-scale patient-centered communication skills training program based on the Calgary-Cambridge Guide. This did not affect the length of the consultations. (J Patient Cent Res Rev. 2021;8:307-314.)

Keywords communication skills training; audio recordings; Calgary-Cambridge Guide; Observation Scheme-12; patient centered care

$\longrightarrow$ ommunication between patients and health care providers is a key component for an effective health care system, and patients are increasingly asking for individualized and personalized care and treatment. ${ }^{1}$ Providing patient-centered care and treatment requires a fundamental knowledge of the patient, not only learning about biomedical aspects but also about the person behind the disease. ${ }^{2,3}$ Consequently, patientcentered communication is required to elicit a patient's experiences, needs, values, and preferences. ${ }^{4}$ Patient-

Corresponding author: Else Dalsgaard Iversen, Health Services Research Unit, Lillebaelt Hospital, Beriderbakken 4, DK-7100, Vejle, Denmark (else.iversen@rsyd.dk) centered communication is defined differently by experts, ${ }^{4,5}$ but the central idea is that treatment and care depends on knowing the patient as a person. ${ }^{6}$ The core elements of this approach to patient care are characterized by addressing the patient's perspective, understanding the patient's psychosocial context, and agreement on a shared plan for treatment and care. ${ }^{7}$

Studies have shown associations between patientcentered communication and positive health outcomes, ${ }^{7-10}$ increased patient satisfaction, ${ }^{11,12}$ reduced medical expenditures, ${ }^{13,14}$ and prevention of malpractice litigation. ${ }^{15,16}$ Previous research has demonstrated that patient-centered communication can be learned through communication skills training, ${ }^{17,18}$ that it improves health care provider (HCP) self-efficacy in patientcentered communication, ${ }^{19}$ and patients' perception of 
care. $^{20,21}$ Evidence from large-scale implementation studies is still scarce, as most studies have examined the effect of training courses designed for HCPs with specific educational backgrounds. ${ }^{18,22,23}$ Heterogeneity among studies is considerable, ${ }^{24}$ without consistency in terms of duration, training strategies, and outcome measurements..$^{25-27}$ Nevertheless, there exists a consensus that communication skills training is useful, mainly when the programs include small group discussions with roleplaying and feedback. ${ }^{28,29}$

These methods were an essential part of a communication skills program titled "Clear-Cut Communication With Patients," which was implemented at a regional hospital in Denmark, 2011-2016. ${ }^{30}$ The program was based on experiences from several earlier studies performed at the hospital ${ }^{19-21}$ and on the Calgary-Cambridge Guide, ${ }^{31}$ a well-known communication skills training and teaching method. However, whether HCPs change their communication behavior to become more patient-centered after the intervention of a large-scale communication skills training program has not been investigated. Furthermore, there was a concern that patient-centered communication would increase the time spent on consultations.

Based on the hypothesis that HCPs would be more patient-centered after participating in communication skills training without affecting consultation length, this study aimed to assess if the HCPs adopted the learned skills from the training, as measured by the Observation Scheme-12 (OS-12).

\section{METHODS}

\section{Study Design and Setting}

The study presented herein assessed the effectiveness of Lillebaelt Hospital's Clear-Cut Communication With Patients program ${ }^{30}$ in a subgroup of HCPs practicing at the hospital's Spine Centre of Southern Denmark outpatient clinic. The Spine Centre provides treatment for patients with back and neck issues by interdisciplinary teams of doctors, nurses, physiotherapists, and chiropractors. Audio recordings were collected in a pre-post design, with Clear-Cut Communication With Patients as the intervention. All participating HCPs had independent encounters with the patients.

\section{Communication Skills Training Program}

All clinical staff was trained in patient-centered communication as part of the overall intervention at Lillebaelt Hospital. ${ }^{30}$ The Calgary-Cambridge Guide is a well-described teaching and training method in clinical communication. ${ }^{31,32}$ It describes the microskills required in each of the 5 domains of the consultation: initiating the session; gathering information; physical examination; explanation and planning; and closing the session. In addition to these 5 domains, the CalgaryCambridge Guide describes how to provide structure to the consultation and how to build a relationship with the patient and relatives. The staff was trained in small groups by HCPs who had been trained as communication trainers via the Clear-Cut Communication With Patients program's "train-the-trainer" education. ${ }^{30}$ Participants worked at the same clinical department but had diverse educational backgrounds.

The training lasted for 3 days. The first 2 days were a mix of theory, discussion, and role-play. These days were followed by a period of approximately 4 weeks in clinical practice during which the participants were encouraged to rehearse the learned skills and video-record one of their encounters. Subsequently, the groups met with the teachers on a third and last day to give and receive feedback on the video recordings.

\section{Data Collection}

Audio recordings from HCP encounters were collected from 2014 to 2015. The HCPs were told to audio-record 10 consecutive encounters before and another 10 encounters after the intervention. Inclusion criteria for encounters were follow-up visits, Danish-speaking patients, consultation duration less than 50 minutes, and only $1 \mathrm{HCP}$ present in the consultation. HCPs informed the patients about the purpose of the study at the beginning of the encounters. Patients were informed that their participation was voluntary and about the possibility of withdrawing consent at any time. The HCPs turned on the audio recorder after the patients had provided informed consent.

\section{Assessment Tool}

The communication skills performed in the clinical encounter were assessed using the OS-12 (Table 1), a 12-item assessment tool developed from the CalgaryCambridge Guide to cover the following domains: initiating the session; gathering information; building a relationship; explanation and planning; providing structure; and closing the session. The OS-12 is validated to rate communications skills based on audio-recorded consultations on a 5-point scale that measures quality level - with $0=$ poor, $1=$ fair, $2=$ good, $3=$ very good, and $4=$ excellent - leading to an overall score ranging from 0 to 48 points. ${ }^{33}$

\section{Coding Procedure}

A maximum of 3 audio recordings was included from every HCP for both pre- and postintervention assessment, given the variation in the number of recorded consultations per HCP (range: 1-10). When an HCP had recorded more than 3 encounters, we systematically excluded the longest 
Table 1. Observation Scheme-12

\begin{tabular}{|c|c|}
\hline Domains & Items and microskills \\
\hline 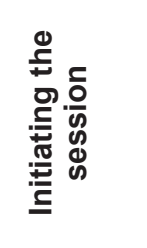 & $\begin{array}{l}\text { Item 1: Identifies problems the patient wishes to address } \\
\text { Microskills: } \\
\text { 1. Greets patients } \\
\text { 2. Introduces oneself, one's role and the nature of the interview } \\
\text { 3. Demonstrates respect and interest; attends to patient's physical comfort } \\
\text { 4. Uses an appropriate opening question/listens attentively } \\
\text { 5. Confirms issues to be discussed/screens for further questions and negotiates the agenda }\end{array}$ \\
\hline 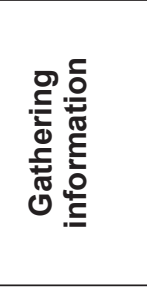 & $\begin{array}{l}\text { Item 2: Clarifies the patient's prior knowledge and desire for information } \\
\text { Microskills: } \\
\text { 1. Listens attentively, allowing the patient to complete statements without interruption and leaving space for patient } \\
\text { 2. Encourages the patient to tell the story of the problem(s) from when it/they first started to the present in his/ } \\
\text { her own words } \\
\text { 3. Uses open and closed questioning techniques, appropriately moving from open to closed questions } \\
\text { 4. Clarifies patient's statements that are unclear or need amplification } \\
\text { 5. Periodically summarizes, invites the patient to correct the interpretation or provide further information }\end{array}$ \\
\hline \multirow{3}{*}{ 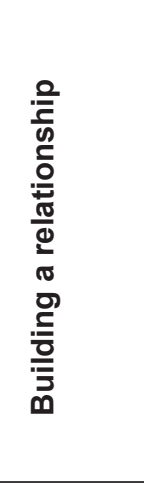 } & $\begin{array}{l}\text { Item 3: Uses easily understood language, avoids jargon } \\
\text { No microskills }\end{array}$ \\
\hline & $\begin{array}{l}\text { Item 4: Uses appropriate nonverbal behaviour } \\
\text { Microskills: } \\
\text { 1. Calm speaking paces } \\
\text { 2. No interruptions } \\
\text { 3. Leaves space for the patient to talk } \\
\text { 4. Pausing } \\
\end{array}$ \\
\hline & $\begin{array}{l}\text { Item 5: Provide support: expresses concern and willingness to help } \\
\text { Microskills: } \\
\text { 1. Accepts the legitimacy of the patient's views and feelings; is not judgmental } \\
\text { 2. Uses empathy to communicate understanding and appreciation of the patient's feelings } \\
\text { 3. Provides support: expresses concern, understanding, and willingness to help }\end{array}$ \\
\hline \multirow{2}{*}{ 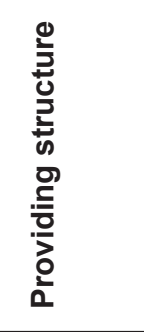 } & $\begin{array}{l}\text { Item 6: Structures the interview in a logical sequence } \\
\text { Microskills: } \\
\text { Progresses from one section to another using 1) signposting, 2) transitional statements, and 3) rationale for the } \\
\text { next section }\end{array}$ \\
\hline & $\begin{array}{l}\text { Item 7: Attends to timekeeping, and keeps the interview on track } \\
\text { Microskills: } \\
\text { 1. Structures the interview based on the Calgary-Cambridge Guide } \\
\text { 2. Attending to timing } \\
\text { 3: Keeping the interview on track }\end{array}$ \\
\hline \multirow{3}{*}{ 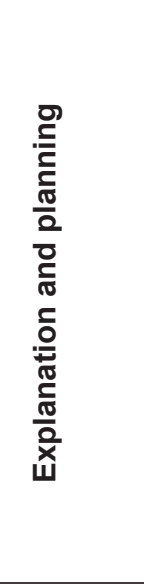 } & $\begin{array}{l}\text { Item 8: Shares thoughts and reflections with the patient } \\
\text { Microskills: } \\
\text { 1. Assesses patient's starting point (preferably using tailored explanations and illustrations) } \\
\text { 2. Provides information in manageable chunks, assesses understanding uses patient's responses as a guide for } \\
\text { the best way to proceed } \\
\text { 3. Providing the correct amount and type of information to individual patients }\end{array}$ \\
\hline & $\begin{array}{l}\text { Item 9: Checks the patient's understanding } \\
\text { Microskills: } \\
\text { 1. Organizes the explanation (uses summarizing) } \\
\text { 2. Assesses the patient's understanding (asks the patient to summarize the information he/she was provided) } \\
\text { 3. Asks the patient what other information would be helpful, addresses patient's needs for information }\end{array}$ \\
\hline & $\begin{array}{l}\text { Item 10: Negotiates a mutual plan of action } \\
\text { Microskills: } \\
\text { 1. Explores options with the patient } \\
\text { 2. Involves the patient in decision-making } \\
\text { 3. Negotiates a mutually acceptable plan }\end{array}$ \\
\hline \multirow{2}{*}{ 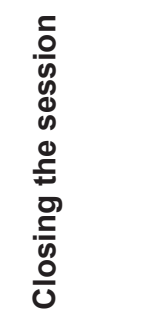 } & $\begin{array}{l}\text { Item 11: Contracts with the patient about next steps } \\
\text { Microskills: } \\
\text { 1. Contracts with the patient about the next steps } \\
\text { 2. Safety nets, eg, phone number and other lifelines }\end{array}$ \\
\hline & $\begin{array}{l}\text { Item 12: Summarizes the session briefly and clarifies the plan of care } \\
\text { Microskills: } \\
\text { 1. Final confirmation of patient understanding } \\
\text { 2. Summarizes the session briefly and clarifies the plan of care } \\
\text { 3. Finally confirms that the patient agrees and is comfortable with the plan }\end{array}$ \\
\hline
\end{tabular}


and the shortest by coding the audio recordings closest to a duration of 21.3 minutes, as this was the mean time obtained from the validation study. ${ }^{34}$

Ratings were performed by 2 experienced HCPs (E.D.I. and H.P.) trained to use the OS-12 and who had previously coded 83 audio recordings with acceptable interrater reliability (intraclass correlation coefficient: 0.74). ${ }^{34}$ One of the raters (E.D.I.) coded the audio recordings for this study. A detailed description of the interrater reliability and rating procedure is provided in a separate paper. ${ }^{34}$ Raters were blinded to information about HCPs' professions and the purpose of the encounters. However, as an experienced rater listening to the audio recordings most often could reveal whether the HCP had been trained in communication skills, it was not considered possible to make an effective blinding of the intervention status.

\section{Outcome Measurement}

The primary outcome was the overall score from the OS-12 when rating communication skills in real-life encounters, which reflected each HCP's performance in patient-centered communication. Overall score was calculated by summarizing the scores from the 12 items into one overall score. Duration of the encounters was obtained from the eligible audio recordings. Data on patient gender and age were collected. Additionally, data on HCP clinical professions and gender were registered.

\section{Statistical Analysis}

The sample size calculation was based on an expected effect size with Cohen's $d$ of 0.4 and standard deviation of 10 for 2 means of independent, normally distributed groups. This calcuation resulted in a requirement of 100 encounters in each of the pre- and postintervention groups to obtain $80 \%$ power. Descriptive statistics were used to describe the characteristics of the sample and possible differences in patient and HCP characteristics between pre- and postintervention groups. A chi-squared test for independence was used for categorical variables, and a $t$ test was used to compare mean difference between 2 unpaired groups for numerical variables. Differences in consultation duration were tested using a $t$ test for both the coded audio recordings and for all of the available audio recordings; afterward, sensitivity analysis was performed with linear mixed-effect model. Furthermore, the correlation between the duration and the overall score was tested using Pearson's $r$, as both variables were normally distributed.

Overall score was calculated for each audio recording, and the improvement was detected using a linear mixedeffect model with HCPs treated as a cluster. Afterward, we performed multiple linear mixed-effect models including the following covariates: patient and HCP gender; patient age; duration of consultation; and HCP profession. Insignificant covariates were removed stepwise from the model until all covariantes were significant. Differences in individual items also were tested by a linear mixedeffect model incorporating the cluster effect within HCPs. All analyses were performed with Stata 16 software (StataCorp LLC). Results with a P-value less than 0.05 were considered significant.

\section{Ethics}

Patients received written and verbal information about the study at the beginning of the consultation. The study was approved by the Danish Data Protection Agency (journal no. 18/36234). In accordance with Danish law, there was no requirement of approval by the Ethical Committee.

\section{RESULTS \\ Descriptive Statistics}

Of 51 eligible HCPs, 43 (84\%) agreed to participate and 514 audio recordings were collected. A total of 131 audio recordings were excluded for the following reasons: technical issues causing missing sound at the beginning or end of the audio recordings $(\mathrm{n}=52)$; duration of consultation longer than 50 minutes $(\mathrm{n}=40)$; poor audio quality ( $\mathrm{n}=34) ; 2 \mathrm{HCPs}$ on the same recording $(\mathrm{n}=2)$; and non-Danish-speaking patients $(\mathrm{n}=3)$. In all, 196 of the 383 available audio recordings were included based on the mean time to be coded. Characteristics of the participating HCPs and patients are shown in Table 2. No differences were found when comparing the characteristics of the participating patients or the HCPs (Table 2).

\section{Main Outcome}

A single linear mixed-effect model was used to analyze pre- and postintervention assessment scores from the OS-12. The results showed significant differences, with a coefficient of 1.3 (95\% CI: $0.35-2.3$; $\mathrm{P}=0.01)$ in favor of the communication skills training. After testing the result with multiple linear mixed-effect models that included all covariants, duration was the only one to be significantly correlated with overall score, as we found no association between overall improvement and gender or age of patients or with HCP gender or professional background (Table 3).

Consultation duration was associated with overall score. Still, when including the covariates into the model, the variable did not influence the main conclusion significantly (coefficient of 1.6 [95\% CI: 0.6-2.5; $\mathrm{P}=0.001]$ ). The linear mixed-effect model showed that 4 of the 12 items had improved significantly (Table 4), specifically item 3 (Uses easily understood language, avoids jargon), item 4 (Uses appropriate nonverbal behavior), item 9 (Checks the patient's understanding), and item 10 (Negotiates a mutual plan of action). 
Table 2. Characteristics of Audio Recordings Selected for Coding

\begin{tabular}{|c|c|c|c|}
\hline Characteristic & $\begin{array}{l}\text { Preintervention } \\
\text { recordings }(\mathrm{N}=99)\end{array}$ & $\begin{array}{l}\text { Postintervention } \\
\text { recordings }(\mathrm{N}=97)\end{array}$ & $P$ \\
\hline HCPs, $n$ & 36 & 35 & \\
\hline Audio recordings per HCP, mean (range) & $2.8(1-3)$ & $2.8(1-3)$ & \\
\hline \multicolumn{4}{|l|}{ Female gender, $\mathrm{n}(\%)$} \\
\hline Patients & $54(54.5)$ & $58(58.8)$ & 0.46 \\
\hline HCPs & $30(83.3)$ & $28(80.0)$ & 0.72 \\
\hline Patient age, mean (SD) & $48(14.4)$ & $49(14.7)$ & 0.73 \\
\hline \multicolumn{4}{|l|}{ Profession of HCPs, n (\%) } \\
\hline Physiotherapist & $18(50.0)$ & $16(45.7)$ & \\
\hline Chiropractor & $7(19.4)$ & $9(25.7)$ & 0.94 \\
\hline Nurse & $9(25.0)$ & $8(22.9)$ & \\
\hline Doctor & $2(5.6)$ & $2(5.7)$ & \\
\hline Encounter duration in minutes, mean (range) & $22.9(7-42)$ & $21.9(6-37)$ & 0.23 \\
\hline
\end{tabular}

HCPs, health care providers; $S D$, standard deviation.

Table 3. Multiple Linear Mixed-Effect Model Comparisons

\begin{tabular}{|c|c|c|c|}
\hline Overall score & Coefficient & $\boldsymbol{P}$ & $95 \% \mathrm{Cl}$ \\
\hline Pre-post & 1.57 & 0.00 & $0.62,2.52$ \\
\hline \multicolumn{4}{|l|}{ Patient characteristics } \\
\hline Gender (ref: male) & 0.60 & 0.26 & $-0.43,1.63$ \\
\hline Age & -0.00 & 0.83 & $-0.39,0.31$ \\
\hline \multicolumn{4}{|l|}{ HCP profession (ref: physiotherapist) } \\
\hline Chiropractor & 0.66 & 0.64 & $-2.08,3.40$ \\
\hline Nurse & 0.52 & 0.86 & $-5.12,6.17$ \\
\hline Doctor & 0.13 & 0.92 & $-2.47,2.72$ \\
\hline Gender of HCP (ref: male) & -1.77 & 0.29 & $-5.04,1.49$ \\
\hline Duration of the encounter & 0.16 & 0.00 & $0.08,0.25$ \\
\hline Constant term & 23.82 & 0.00 & $20.33,27.31$ \\
\hline \multicolumn{4}{|l|}{ Random-effects parameters } \\
\hline Variance of random intercept for each HCP & 9.20 & & $5.28,16.00$ \\
\hline Residual variance & 10.05 & & $8.04,12.56$ \\
\hline
\end{tabular}

HCP, health care provider.

\section{Duration of Consultations}

Consultations were, on average, 1.0 minutes shorter after the communication skills training for the 196 coded audio recordings. The difference between pre- and postintervention assessments was not significant (Table 2). Analysis of the consultation duration for all 383 available audio recordings showed no significant difference between before and after the training course (data not shown); consultations were, on average, 55 seconds shorter after the intervention. These results persisted when conducting sensitivity analysis: for the coded audio recordings, the mixed-effect model revealed a coefficient of -1.4 (95\% CI: $-2.9-0.2 ; \mathrm{P}=0.09)$, whereas the coefficient was $-0.8(95 \%$ CI: $-2.5-1.0 ; \mathrm{P}=0.39$ ) for all the available audio recordings. Preintervention correlation between the overall score from the OS-12 and consultation duration was 0.28 $(\mathrm{P}=0.01)$. However, postintervention correlation $(0.17$; $\mathrm{P}=0.10$ ) was not significant. 
Table 4. Mean Pre- and Postintervention Assessment Scores Per Program Items

\begin{tabular}{|c|c|c|c|c|}
\hline Item & & $\begin{array}{l}\text { Pre, } \\
\text { mean }\end{array}$ & $\begin{array}{l}\text { Post, } \\
\text { mean }\end{array}$ & $P^{*}$ \\
\hline 1 & Identifies problems the patient wishes to address & 2.34 & 2.47 & 0.20 \\
\hline 2 & Clarifies the patient's prior knowledge and desire for information & 2.22 & 2.11 & 0.17 \\
\hline 3 & Uses easily understood language, avoids jargon & 3.64 & 3.77 & 0.02 \\
\hline 4 & Uses appropriate nonverbal behavior & 3.06 & 3.42 & 0.00 \\
\hline 5 & Provides support: expresses concern and willingness to help & 2.67 & 2.63 & 0.35 \\
\hline 6 & Structures interview in a logical sequence & 2.17 & 2.29 & 0.19 \\
\hline 7 & Attends to timekeeping, and keeps the interview on track & 1.93 & 2.12 & 0.09 \\
\hline 8 & Shares thoughts and reflections with the patient & 2.17 & 2.27 & 0.12 \\
\hline 9 & Checks the patient's understanding & 1.78 & 2.08 & 0.00 \\
\hline 10 & Negotiates a mutual plan of action & 2.23 & 2.49 & 0.01 \\
\hline 11 & Contracts with the patient about next steps & 2.66 & 2.83 & 0.30 \\
\hline 12 & Summarizes the session briefly and clarifies the plan of care & 2.06 & 2.11 & 0.69 \\
\hline
\end{tabular}

*per linear mixed-effect model.

\section{DISCUSSION}

This study evaluated if a large-scale training program, Clear-Cut Communication With Patients, changed HCPs' behavior in real-life consultations to a more patientcentered approach without lengthening consultation time. Based on the ratings of audio recordings, we found a significant improvement in patient-centeredness, with no effect on duration of encounters. Item analyses indicated that the training program might have led to less jargon, more checking of patient understanding, and negotiation of a mutual plan for action.

Overall score was significantly correlated with duration for the preintervention assessment group, indicating that more time spent with the patient increases the amount of patient-centered communication skills used. After the HCPs in this study were trained in the program, they increased the use of patient-centered communication skills without this affecting consultation duration, which was not correlated to the overall score. This indicates an effective use of the learned patient-centered communication skills.

The training changed HCPs' communication behavior to be more patient-centered, as they used more patientfriendly words, avoided jargon (ie, item 3 on the OS-12), and changed their tone of voice (item 4). Other studies have shown that HCPs tend to underestimate their use of medical jargon, ${ }^{35}$ and our findings may indicate, as have others, ${ }^{30}$ that using methods like role-playing and feedback on actual encounters (video) can give HCPs an insight into their performance and inspire them to change their way of communicating.
Our study also revealed a change in the HCP behavior according to the 3 items within the domain of "explanation and planning." We found that the HCPs rarely checked for patients' understanding (item 9) before attending the training course. However, after the training course, a significant improvement was found on this particular item and another (item 10 - Negotiate a mutual plan of action), indicating increased patient involvement in clinic visits. Such improvement is essential, as the literature indicates that HCPs should not rely on their own assumptions about patient knowledge of the provided information ${ }^{36,37}$ but rather should ask and check. It is positive that the training significantly increased the score on these items, even though the items' mean scores remained low and therefore leave room for further improvement. These results demonstrate that teaching communication skills based on the Calgary-Cambridge Guide may lead to the improvement of the microskills essential for succeeding with patient involvement and shared decision-making, ${ }^{38}$ just as skills like "leaving space for the patient to talk" and "not interrupting the patient" promote opportunities for the patients to have a higher impact on the conversation and treatment plans.

Despite HCPs becoming more patient-centered in their communication behavior, encounters did not last longer post-skills training, a finding similar to prior reports. ${ }^{23,39}$ This may encourage HCPs to use skills that characterize patient-centered communication without worrying about spending extra time they do not feel is available.

\section{Limitations}

HCPs were instructed to include patients consecutively. However, in the busy clinical reality of the outpatient 
clinic, each HCP did not always manage to do so, which may have introduced a source of bias. Unfortunately, the study design did not allow us to identify the total number of patients who met the inclusion criteria, preventing us from quantifying the magnitude of the problem. Another limitation is lack of data on patients' clinical outcomes. One could assume that clinical characteristics would have influenced consultation length; as raters could not be blinded to the condition of the patient, it might have been beneficial to control for clinical outcomes. That it was not possible to blind raters to information about intervention status may be considered a study limitation that, in an effort to accomplish significant results, could lead to false high points in the postintervention group and false low points in the preintervention group. However, the nature of the OS-12 is descriptive, reporting and calculating the number of demonstrated microskills and thus measuring what actually happens in the consultation. Consequently, overall scores were primarily based on an objective calculation of demonstrated skills, and subjective impressions were minimized by making the codebook as detailed as possible.

Another study limitation was the rating of nonverbal behavior (item 4) based on audio recordings, as this did not allow observation and rating of actual body language. To overcome this limitation, we chose to rate each HCP's tone of voice by 1) calm speaking pace, 2) no interruptions of the patient, 3) leaving space for the patient to talk, and 4) pausing. ${ }^{34}$ As the study intended to examine patientcentered communication on average consultations, the longest and shortest consultations were excluded from analyses. By doing so, we might have missed some aspect of importance for the evaluation. In future studies, it may be of interest to examine which consultations last longer and to elucidate the reasons for it.

\section{CONCLUSIONS}

Health care providers can improve their communication behavior when they are trained in small groups, based on the Calgary-Cambridge Guide. Our nonblinded raters found that overall performance scores showed significant improvement in 4 of 12 items on the Observation Scheme-12 measurement tool. Also, the duration of consultations did not increase following the patient-centered communication skills training, nor was communication improvement dependent on HCP educational background.

While the content of the training program assessed in this Denmark-set study is very similar to communication training programs used in other countries, the structure and length of programs may differ. It is important to adjust programs to account for local needs and circumstances. ${ }^{40}$

\section{Patient-Friendly Recap}

- Prior studies have shown patient-centered communication by care providers results in better health outcomes, increased patient satisfaction, and reduced medical expenditures.

- At a hospital in Denmark, clinic staff received group training in communication skills derived from the Calgary-Cambridge Guide, which included elements of patient encounters such as information gathering, physical examination, relationship building, and explanation/planning.

- Communication skills training helped health care providers improve the patient-centered nature of their care without increasing the length of an average clinic visit.

\section{Acknowledgments}

We acknowledge the patients and the health care professionals at the outpatient clinic at the Spine Centre of Southern Denmark, Lillebaelt Hospital, for their willingness to participate in the study, as well as Troels Præst Andersen for collecting the audio recordings.

\section{Author Contributions}

Study design: Kofoed, Ammentorp. Data acquisition or analysis: all authors. Manuscript drafting: all authors. Critical revision: all authors.

\section{Conflicts of Interest}

None.

\section{Funding Sources}

The Clear-Cut Communication With Patients skills training program is funded by the University of Southern Denmark, Region of Southern Denmark, and Lillebaelt Hospital.

\section{References}

1. McCormack B, van Dulmen A, Eide H, Skovdahl K, Eide T (eds). Person-Centred Healthcare Research. John Wiley \& Sons; 2017.

2. Bensing J. Bridging the gap. The separate worlds of evidencebased medicine and patient-centered medicine. Patient Educ Couns. 2000;39:17-25. CrossRef

3. Gerwing J, Gulbrandsen P. Contextualizing decisions: stepping out of the SDM track. Patient Educ Couns. 2019;102:815-6. CrossRef

4. Epstein RM, Franks P, Fiscella K, et al. Measuring patientcentered communication in patient-physician consultations: theoretical and practical issues. Soc Sci Med. 2005;61:1516-28. CrossRef

5. Stewart M, Brown JB, Weston WW, McWhinney IR, McWilliam CL, Freeman TR. Patient-Centered Medicine: Transforming the Clinical Method, Third Edition. Radcliffe Publishing; 2014.

6. Epstein RM. The science of patient-centered care. J Fam Pract. 2000;49:805-7. 
7. Street RL Jr., Makoul G, Arora NK, Epstein RM. How does communication heal? Pathways linking clinician-patient communication to health outcomes. Patient Educ Couns. 2009;74:295-301. CrossRef

8. Georgopoulou S, Prothero L, D'Cruz DP. Physician-patient communication in rheumatology: a systematic review. Rheumatol Int. 2018;38:763-75. CrossRef

9. Haskard Zolnierek KB, Dimatteo MR. Physician communication and patient adherence to treatment: a metaanalysis. Med Care. 2009;47:826-34. CrossRef

10. Morasso G, Caruso A, Belbusti V, et al. Improving physicians' communication skills and reducing cancer patients' anxiety: a quasi-experimental study. Tumori. 2015;101:131-7. CrossRef

11. Venetis MK, Robinson JD, Turkiewicz KL, Allen M. An evidence base for patient-centered cancer care: a metaanalysis of studies of observed communication between cancer specialists and their patients. Patient Educ Couns. 2009;77:379-83. CrossRef

12. Boissy A, Windover AK, Bokar D, et al. Communication skills training for physicians improves patient satisfaction. $J$ Gen Intern Med. 2016;31:755-61. CrossRef

13. Epstein RM, Franks P, Shields CG, et al. Patient-centered communication and diagnostic testing. Ann Fam Med. 2005;3:415-21. CrossRef

14. Schwartz A, Weiner SJ, Weaver F, et al. Uncharted territory: measuring costs of diagnostic errors outside the medical record. BMJ Qual Saf. 2012;21:918-24. CrossRef

15. Ferguson B, Geralds J, Petrey J, Huecker M. Malpractice in emergency medicine - a review of risk and mitigation practices for the emergency medicine provider. J Emerg Med. 2018;55:659-65. CrossRef

16. Vukmir RB. Medical malpractice: managing the risk. Med Law. 2004;23:495-513.

17. Rao JK, Anderson LA, Inui TS, Frankel RM. Communication interventions make a difference in conversations between physicians and patients: a systematic review of the evidence. Med Care. 2007;45:340-9. CrossRef

18. Moore PM, Rivera S, Bravo-Soto GA, Olivares C, Lawrie TA. Communication skills training for healthcare professionals working with people who have cancer. Cochrane Database Syst Rev. 2018;7(7):CD003751. CrossRef

19. Norgaard B, Ammentorp J, Ohm Kyvik K, Kofoed PE. Communication skills training increases self-efficacy of health care professionals. J Contin Educ Health Prof. 2012;32:90-7. CrossRef

20. Ammentorp J SS, Kofoed PE, Mainz J. Effects of a communication course for clinicians on parents' perception of care - a randomized controlled trail. Scand J Caring Sci. 2009;23:506-17. CrossRef

21. Nørgaard B, Kofoed PE, Ohm Kyvik K, Ammemtorp J. Communication skills training for health care professionals improves the adult orthopaedic patient's experience of quality of care. Scand J Caring Sci. 2012;26:698-704. CrossRef

22. Fischer F, Helmer S, Rogge A, et al. Outcomes and outcome measures used in evaluation of communication training in oncology - a systematic literature review, an expert workshop, and recommendations for future research. BMC Cancer. 2019;19(1):808. CrossRef

23. Fossli Jensen B, Gulbrandsen P, Dahl FA, Krupat E, Frankel RM, Finset A. Effectivensess of a short course in clinical communication skills for hospital doctors: results of a crossover randomized controlled trial. Patient Educ Couns. 2011;84:163-9. CrossRef
24. Barth J, Lannen P. Efficacy of communication skills training courses in oncology: a systematic review and meta-analysis. Ann Oncol. 2011;22:1030-40. CrossRef

25. Kissane DW, Bylund CL, Banerjee SC, et al. Communication skills training for oncology professionals. J Clin Oncol. 2012;30:1242-7. CrossRef

26. Dwamena F, Holmes-Rovner M, Gaulden CM, et al. Interventions for providers to promote a patient-centred approach in clinical consultations. Cochrane Database Syst Rev. 2012;12:CD003267. CrossRef

27. Ditton-Phare P, Loughland C, Duvivier R, Kelly B. Communication skills in the training of psychiatrists: a systematic review of current approaches. Aust $N Z \mathrm{~J}$ Psychiatry. 2017;51:675-92. CrossRef

28. Berkhof M, van Rijssen HJ, Schellart AJM, Anema JR, van der Beek AJ. Effective training strategies for teaching communication skills to physicians: an overview of systematic reviews. Patient Educ Couns. 2011;84:152-62. CrossRef

29. van der Vleuten C, van den Eertwegh V, Giroldi E. Assessment of communication skills. Patient Educ Couns. 2019;102(11):2110-2113.

30. Ammentorp J, Graugaard LT, Lau ME, Andersen TP, Waidtløw K, Kofoed PE. Mandatory communication training of all employees with patient contact. Patient Educ Couns. 2014;95:429-32. CrossRef

31. Silverman J, Kurtz S, Draper J. Skills for Communicating With Patients, Third Edition. CRC Press; 2013.

32. Kurtz SM, Silverman JD. The Calgary-Cambridge Referenced Observation Guides: an aid to defining the curriculum and organizing the teaching in communication training programmes. Med Educ. 1996;30:83-9. CrossRef

33. Ammentorp J, Thomsen JL, Jarbøl DE, et al. Comparison of the medical students' perceived self-efficacy and the evaluation of the observers and patients. BMC Med Educ. 2013;13:49. CrossRef

34. Iversen ED, Wolderslund MO, Kofoed PE, et al. Codebook for rating clinical communication skills based on the CalgaryCambridge Guide. BMC Med Educ. 2020;20(1):140. CrossRef

35. Howard T, Jacobson KL, Kripalani S. Doctor talk: physicians' use of clear verbal communication. J Health Commun. 2013;18:991-1001. CrossRef

36. Richard C, Glaser E, Lussier MT. Communication and patient participation influencing patient recall of treatment discussions. Health Expect. 2017;20:760-70. CrossRef

37. Engel KG, Heisler M, Smith DM, Robinson CH, Forman JH, Ubel PA. Patient comprehension of emergency department care and instructions: Are patients aware of when they do not understand? Ann Emerg Med. 2009;53:454-61.e15. CrossRef

38. Towle A, Godolphin W. Framework for teaching and learning informed shared decision making. BMJ. 1999;319:766-71. CrossRef

39. Maatouk-Bürmann B, Ringel N, Spang J, et al. Improving patient-centered communication: results of a randomized controlled trial. Patient Educ Couns. 2016;99:117-24. CrossRef

40. Ammentorp J, Bigi S, Silverman J, et al. Upscaling communication skills training - lessons learned from international initiatives. Patient Educ Couns. 2021;104:352-9. CrossRef

(C) 2021 Advocate Aurora Health, Inc. 